\title{
The obstacle study about the charging platform of contact phone
}

\author{
Hu Wenfei \\ Wenzhou Vocational \& Technical College, Wenzhou. 325035 \\ 61230934@qq.com
}

Keywords: contact; Platform; in common use; charging.

\begin{abstract}
Phones are the most important part of people's life nowadays. The investigation found out that mobile phone users always take phones with them when they going out. The frequency of using phones is quite high, people checking their phones almost every 10 minutes, playing phones for a while every an hour. No matter where they go, the phones always company with them such as in the bus, the subway, the train. Mobile phones are the best tools for killing time. In order to meet various kinds of charging requirements for mobiles phones with different types, I designed this public phone charging station which combines with the knowledge of humanized design, ergonomics, color design and design psychology and other relevant professional knowledge of industrial design.
\end{abstract}

\section{Introduction}

At present in public, people can see the universal phone chargers only at the station, shopping malls and other places with more quantity of people. Because of its cold appearances and paying one RMB only charging for ten minutes which cannot meet the peoples' needs, it still has not been widely used. Besides, the purposes of public facility constructions are to provide conveniences for people, and also they should be free. In order to make the appearance fashionable, operation more convenient and simpler and more comfortable for users, I consider all aspects of functions to improved the design of existing products through combining the knowledge of ergonomics and humanized design.

\subsection{The present market situation about contact charging platform}

Through modifying the designs of the existing universal charging station, at the same time, adding new features and new ideas, a brand new public phone charging station is amazingly born.

\subsection{The feasibility analysis of the project}

People's urgent requests to phone charging devices are helpful to improve the image of a city. Currently, the productions of public universal phone chargers on the market are not very mature, so there is a lot of room to develop and improve. As a designer, should not only consider the new modifications of appearances, but also care more about the innovation of operational systems, functions and utilities. If you want to make a better phone charging station, more analysis and improvements are indispensible. Only to break the old features of the existing products, a better one can be created, which is also the mission of a designer.

\section{The survey analysis}

\subsection{The development of the mobile phone charging station}

Mobile phone charging station firstly appeared at the train station for passengers whose mobile phones without electricity and needs emergency charging. It was installed at the shopping malls and banks afterward. At first, the principle of design is paying for charging. People are hard to accept the design at the beginning, but they started to use it out of curiosity and the emergency needs. However, all kinds of problems also arises at the same time, such as people cannot find the same mobile phone models, it hardly to keep up with cell phone renewal speed, the effect of the paying for charging cannot satisfy people's demands. 


\subsection{The market demands and present situations}

One more advanced station among the existing stations on the market is a kind of intelligent mobile charging station typed of SY-SG-L-12.See picture1. According to the requirements of people, the launch of SY-SG-L-12 typed mobile intelligent charging stations is through a detailed market research, market analysis, bringing together all brands of mobile phones. Its performance is stable, structure is reasonable, appearance is fashionable, and added high-tech factors also. It is a powerful guarantee for people's charging requirements. To adapt to the ubiquitous smart phone brands, such as apple, MI, SAMSUNG, NOKIA, LG, HTC, LENOVO etc, this station is installed with two universal chargers, a USB interface, nine straight charging lines.

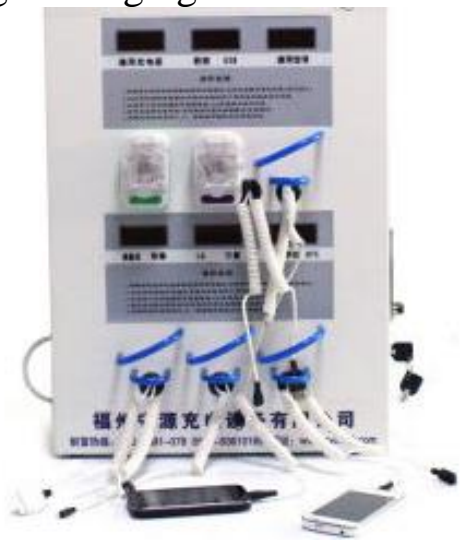

Picture1. Intelligent mobile charging station

\subsection{The analysis report}

After years of development, although to a certain extent, this charging station can satisfy people's needs, it cannot keep up with the pace of mobile phone upgrade, such as wireless charging device hardly to satisfy people's needs. We can see the potential of the development is extremely huge, we should accordingly design a product demanded by modern people.

\section{Design expression}

\subsection{Rhino model is shown in picture 2.}
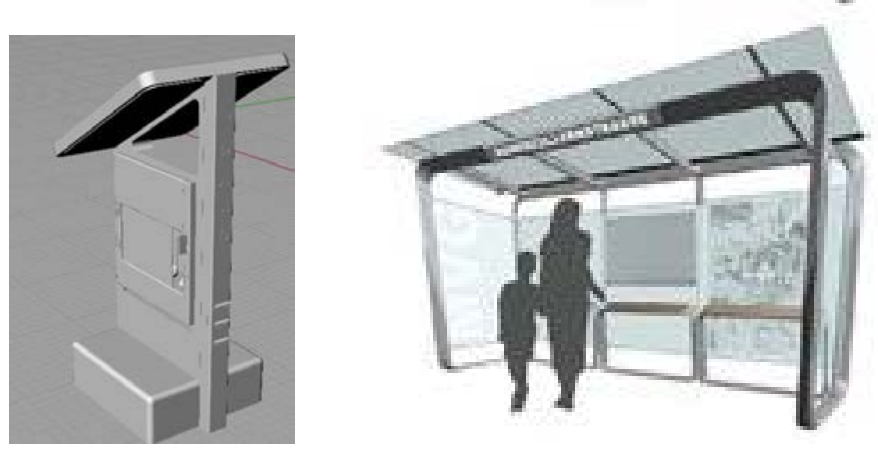

Picture2 Rhino modeling 


\subsection{Effect pictures are shown in picture 3.}
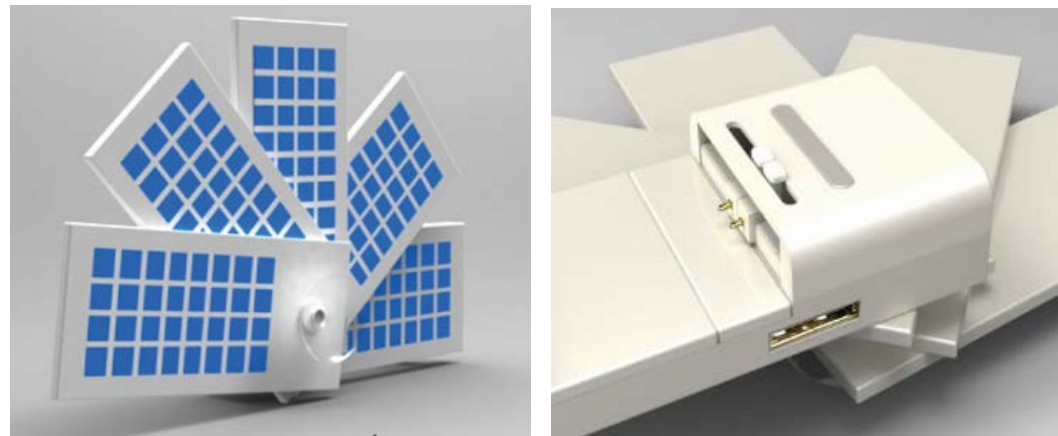

Picture3.effect pictures

3.3 Hand sketching and effect pictures are shown in picture4.

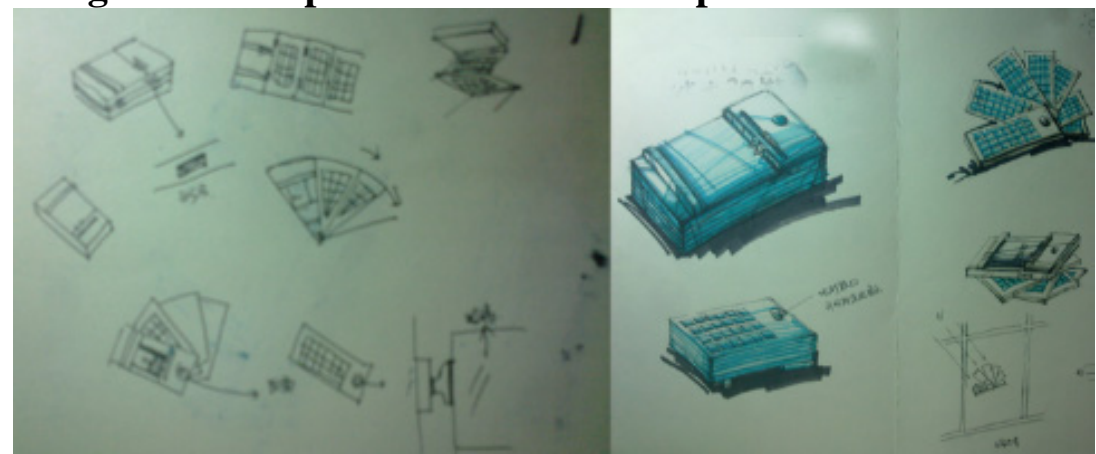

Picture 4.Effect pictures

\subsection{The environment for chargers is shown in picture 5}

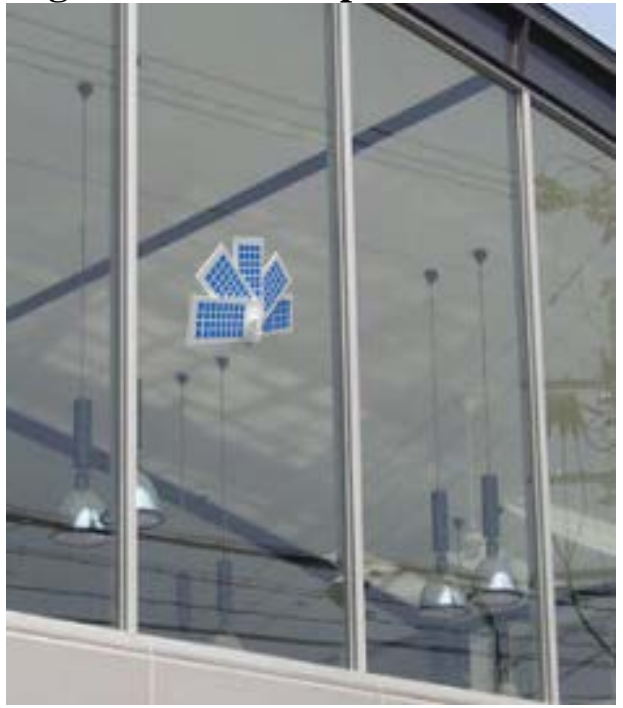

Picture5. The environment for chargers

\section{The design principles}

\subsection{Function realization}

The key point to function realization depends on energy storage and release of solar charging pad, and voltages processing measures. The choice of structure plays a critical role for function stability too. To this kind of high-end electronic product, we try to avoid using some small parts for the organizations and structures, reducing the complexity of structures as much as possible, and preventing the causes of potential safety hazards. Above all, we need to reach the goal of function realization.

The direct function of this design is to charge the mobile phones. The storage of additional electrical power can be used as lighting at night. At the same time, this station provides free seats, 
wireless WIFI, etc. All these functions play their roles respectively and coordinate with each other perfectly.

\subsection{Materials selection}

The materials for public universal mobile phone charging station are: 2.0 thickness stainless steel with spray paint processing, PVC, glass, pines etc.

The materials for solar battery charging board are: glass, EVA, TPT, aluminum alloy frames.

The materials for mobile phone charging stations: stainless steel frames, PVC, auxiliary structures, glass windows, and pine board seats.

\subsection{Ergonomics analysis}

Research field and application scope about ergonomics are quite wide. Superficially, ergonomics mainly studies the problem of "comfort problem" in the work and activities. Actually, it refers to the human factors, machine factors and various complicated factors in environment systems.

Human senses: including visual, hearing, smelling, and other feelings.

Transmission and processing of information: mainly including accepting, storing, and transferring, outputting and expressing information, etc.

Psychological states during operation: During people in the process of operating the machine, Psychological states mainly include the ability of psychological reaction and the ability to adapt, also include psychological factors that may cause errors in all situations.

Information display system: Information display system is to convey its working status to the people, and is a device to give feedback after being controlled and operated by human. The devices mainly include all kinds of instrument panels and displays.

Man-machine interface: Man-machine interface display system is a combination of the control system and display system. The display system and the control system keep certain corresponding relationships, and both systems are also allowed to keep timely contact and dialogue. With the interface, it is more convenient to operate.

Ergonomics requires the product design should meet people's physiological and psychological needs to make people comfortably and effectively operate the machine. But the industrial design should not only consider the ergonomics, but also consider all aspects of the product and analyze all kinds of influences to people. Although to the same problems, such as comfort and humanization, industrial design considers the conditions more comprehensive than the man-machine engineering does.

\subsection{Environmental factors}

Environmental factors are also important factors for the man-machine system. The suitable environment can improve the work efficiency and work force, keep people healthy, and improve the performance and reliability of the machine.

The influence of environment to man-machine system is shown in many ways, mainly including lighting, temperature, humidity, noise, vibration, magnetic force, gravity, climate, color, layout, size, etc.

\subsection{The problem of application}

The goal of ergonomics is to design machines and tools according to the human ability. Although convenience and comfort are the non-stop pursuits of human being, people should not only rely on ergonomics, dreaming that we can get all products used conveniently by ergonomics. There is not a 100 percent perfect design, which is only a dream to pursuit. Even some people think the design should not be perfect to some degree. According to the principle of biological evolution, if animals and plants live under the optimum conditions, their resistance to harsh living conditions will reduce. Safety in design should be guaranteed, but keeping some inconvenient factors is also allowed. Appropriately designing a defect is one of the key points in ergonomics. 


\subsection{The function introduction of each part}

\subsubsection{The solar panels}

Solar panels absorb sunlight. Through the photoelectric effect or photochemical effect, solar radiation is directly or indirectly converted into electricity. The electricity is used for charging the mobile phone. In the night, the stored electricity is also used for road lighting.

\subsubsection{The billboard}

The billboard is used for advertising. Advertising fees can be used to the daily maintenance for charging stations. It not only propagandize enterprise image but also enhance the overall image of the city.

\subsubsection{All types of chargers}

The types of mobile phone charger includes: all kinds of cable chargers, universal chargers, mobile power, wireless chargers, etc. Our mobile phone charging station also provides rest seats and free Internet access WIFI.

\section{Summary}

While people are charging their mobile phones, they can enjoy the comfort brought by this new station. Charging power is totally from solar energy, alleviating the power shortage problem. At the same time, the stored electricity can be used as lighting. Our charging station is equipped with seats and wireless WIFI for pedestrians to help people enjoy the comfortable process of charging. Choosing shallow gray and blue lines as staple colors for the station provides the feeling of clean, quiet and elegant. And these colors also match well with city street scenes, just like naturally blend together, rather than incompatible with each other. A good design is not only a drawing, but also to make a product from the perspective of users under all kinds of restrictions.

\section{References}

[1] JIANG Jin-chen, PI Yong-sheng.Principles and methods ofproduct design[M].Chongqing: Southwest China Normal University Press, 2009.

[2] JIANG Jin-chen, PI Yong-sheng.Principles and methods of product design[M].Chongqing: Southwest China Normal University Press, 2009.

[3] PI Yong-sheng.Recognition of the role of industrial design[J].Zhuangshi, 2010 (10) : 129-130.

[4] WEI Yong-xia.User Experience Goals Study in Product Design[J].Packaging Engineering, 2011, 32 (16) : 78-81.

[5] PI Yong-sheng.Product Semantic Design[M].Chongqing: SouthwestChina Normal University Press, 2009. 